\title{
RENÉ MAJOR
}

Leneide Duarte-Plon, de Paris

$\mathrm{N}$ ano em que o mundo inteiro se prepara para comemoar os 150 anos de nascimento de Sigmund Freud, os psicanalistas René Major e Chantal Talagrand vão Iançar uma biografia do Pai da Psicanálise, por encomenda da editora Gallimard.

Mas o idealizador dos Estados Gerais da Psicanálise - 0 grande encontro de psicanalistas realizado no ano 2000, em Paris - e promotor do debate entre Jacques Derrida e Jean Baudrillard, 'Por que a guerra?', às vésperas da invasão do Iraque por George Bush, não vai escrever uma biografia convencional de Freud. Ele pretende mostrar por que, mais de cem anos depois da invenção da psicanálise, Freud continua a ser atacado pelo caráter subversi vo de sua descoberta.

"O livro começa pelo auto-de-fé em Berlim. Se levamos em conta o inconsciente, a cronologia rígida não tem mais muito sentido. A própria história em geral e a historiografia no que concerne à psicanálise não pode mais ser escrita como se fazia antes de Freud. Freud revolucionou até mesmo a maneira de se escrever a História", assegura René Major, fumando um charuto em seu consultório de frente para o Sena, num dia muito frio de inverno.

Sem citar nomes nem entrar em detalhes sobre as rivalidades na herança Iacaniana, Major critica a necessidade de vassalagem e a "posição de soberania que se transmitiu na herança lacaniana e continua a causar problema hoje".

O lançamento da biografia de Freud está previsto para abril, mês do nascimento do criador da psicanálise. N esta entrevista exclusiva para a revista Trópico, o autor de De l'élection (Da eleição) defende o engajamento político dos psicanalistas e suas responsabilidades com a História, comenta o livro de Freud

* Publicada em Trópico, revista cultural on-line. 
M oisés e o monotésmo e explica que a teoria da raça ariana pura entrava em colisão com a tradição religiosa da eleição do povo judeu.

LENEIDE DUARTE-PLON - Este ano, os 150 anos do nascimento de Freud serão comemorados no mundo todo. Como os psi canali stas franceses vão festejar este aniversário?

RENÉ MAJOR - Não sei de nada em particular, a não ser do livro que estou escrevendo com Chantal Talagrand, uma biografia de Freud, encomendada pela Gallimard para abril, mês do nascimento de Freud. Decidimos descobrir como e por que periodicamente querem queimar Freud. Queremos mostrar que, hoje, as hostilidades se revelam de forma particular com o retorno de um neopositivismo, a idéia da eficácia terapêutica, da avaliação, do que seria a ciência. Querem tirá-lo da universidade e da psiquiatria. Estão tentando domesticar a prática psicanalítica, que é, na essência, politicamente subversiva.

A psicanálise incomoda por causa do pensamento sociopolítico de Freud.Vêse através de seu percurso como isso acontece e como ele pôde dizer: "Eu lutei toda minha vida contra minhas ilusões pessoais e contra as ilusões da religião e da política". Através dessa biografia, vamos tentar mostrar, ao contrário da maioria das biografias de Freud que se desenvolvem da forma histórica clássica no plano cronológico, como a introdução dos tempos misturados faz com que possamos começar não no começo, porque o começo já estava também no fim.

0 livro começa pelo auto-de-fé em Berlim. Se levamos em conta o inconsciente, a cronologia rígida não tem mais muito sentido. A própria história em geral e a historiografia no que se refere à psicanálise não pode mais ser escrita como se fazia antes de Freud. Freud revolucionou até mesmo a maneira de se escrever a História.

LDP - Freud declarou- se contra a pena de mortee manteve uma correspondência com Einstein sobre a guerra, em 1933. Por que os psicanali stas hoje se envolvem tão pouco no debate político, seja na França seja no estrangeiro?

RM - Há diversas maneira de se ter uma participação política. Pode-se escrever um artigo sobre os acontecimentos políticos e pode-se tomar posição com um manifesto. Freud não fez declarações intempestivas sobre o que se passava no plano político. Ele fez uma análise. Na sua correspondência com Einstein ele não diz "sou contra a guerra" ou "sou contra a pena de morte". De maneira mais exemplar ainda, em Moisés e o monotésmo, ele divulga outra versão para a história de Moisés, contrariando parte dos pensadores judeus. 0 que ele faz? É um texto muito complexo, com vários níveis de leitura. Para tomar apenas um, ele mostra M oisés como um nobre que retoma o monoteísmo egípcio que tinha sido esquecido.

Freud faz de Moisés alguém que reabilita no povo judeu seu amor-próprio, esmagado no Egito, e o leva para a Terra Prometida. Mas, como são os anos do 
crescimento do nacional-socialismo (e na correspondência de Freud el e fala disso o tempo todo), há uma frase absolutamente exemplar na qual ele pergunta por que o judeu é objeto de perseguição e por que mais que nunca se vive a pior barbárie, com uma regressão a uma época pré-histórica? Porque o nacionalsocialismo desenvolve uma idéia delirante de ciúme em relação ao povo judeu. Freud diz: "Como se eles acreditassem na crença do povo judeu de que ele é 0 povo eleito" . 0 que faz Freud? Ele desconstrói a crença do povo judeu, ele diz, em suma: "Os judeus não podem pretender que eles são o povo eleito".

Foi Moisés quem Ihes disse: "vocês são o povo el eito", para restaurar o amorpróprio daquele povo. Hitler diz explicitamente: "Não pode haver dois povos eleitos, ou eles ou nós". Hitler, no fundo, retoma a idéia de que a raça ariana é a detentora da eleição divina. Essa análise de Freud chocou muito, embora ele nunca tenha sido sionista, mesmo que nunca tenha negado sua origem judaica. Freud desconstrói a idéia de eleição do povo judeu. Como hoje, poder-se-ia fazer uma análise do que se passa na periferia de Paris, buscando, e isso seria uma análise freudiana, encontrar sobre o que essa violência repousa há duas ou três gerações de imigrantes. Como a França recebeu os pais ou os avós e como foi transmitida a idéia de que eles eram aceitos, mas não por boas razões, ao contrário da eleição. E é mesmo muito possível que depois de uma geração silenciosa uma outra se revolte contra essa idéia de não ser de fato levada em consideração como os outros franceses, de não ser recebida da mesma forma no trabalho, na hora de alugar um apartamento. Neste caso, também se pode assinar uma petição, pode-se protestar efetivamente e pode-se também fazer a análise histórica.

É verdade que a grande maioria dos psicanalistas, e isso é grave, não leva em conta que essa prática é essencialmente política, na medida que visa à liberdade do sujeito e que esta liberdade não é de todo independente da liberdade do cidadão. E como é possível para a maioria dos analistas embarcar, como os outros cidadãos, nessa espécie de neofascismo galopante, tanto mais eficaz por ser mesmo galopante e se manifestar em toda parte e ser aprovado pela maioria da população. Acho que a psicanálise, através dos psicanalistas, tem uma responsabilidade considerável.

LDP - Recentemente, foi realizado emViena um simpósio para comemorar os 50 anos da conferência de Lacan, na qual ele defendia o retorno a Freud. Se Lacan não tivesse realizado este retorno, qual teria sido o percurso da psicanálise?

RM - Acabo de escrever uma conferência sobre as ambigüidades do retorno a Freud. Penso que o retorno a Freud realizado por Lacan era necessário, mas é preciso perguntar a que ele serviu. Acho que o retorno a Freud defendido por Lacan é o retorno do próprio Lacan a Freud; é, em parte, uma apropriação de Freud. Mas isso é a história da leitura feita por Jacques Derrida do seminário 
'A carta roubada' e da instituição que Lacan fundou com o nome de Freud. E isso demandaria uma longa demonstração.

LDP - Pode falar dessa ambigüi dade?

RM - Acho que Lacan tinha razão de querer salvar ao menos em parte a psicanálise na França. Para apoiar seu plano de salvamento, havia o ele constatava que se passava com a psicanálise no mundo.

\section{LDP - Lacan via a psicanálise num impasse?}

RENÉ - Ele usa palavras muito duras, diz que é preciso "limpar os estábulos de Augias", mas é um julgamento um pouco sumário. Eu estava no Instituto de Psicanálise nessa época; havia grandes nomes, como Schlumberger e Pasche, que não se pode dizer que desonravam a psicanálise. Isso tudo foi vivido numa luta política no interior da instituição psicanalítica e do movimento psicanalítico na França, que é preciso reconstituir no seu contexto, e que é muito complicado.

\section{LDP - Esse retorno a Freud era fundamental?}

RM - Sim, mas ao mesmo tempo eu diria que a contribuição de Lacan, com a discussão que ele introduz, em confrontação com a literatura, a filosofia, a antropologia, com Lévi-Strauss etc., foi muito importante para a implantação da psicanálise na França no plano cultural.

Desse ponto de vista, não teria havido essa implantação específica na França se as coisas tivessem se passado como na Inglaterra ou mesmo nos Estados Unidos, onde a psicanálise ficou fechada sem se difundir na cultura. Isso é muito importante e considero que Lacan teve nisso um papel essencial para que tenha havido Deleuze, Ricoeur, Derrida, Hélène Cixous na literatura, e muitos outros que foram impregnados pelo pensamento psicanalítico, o que não aconteceu em outros países. Ele teve um papel essencial na difusão do pensamento psicanalítico na cultura.

Se examino o que se tornou o movimento lacaniano, hoje, a partir da fundação da Escola Freudiana, vejo que Lacan apropriou-se do retorno a Freud de uma maneira soberana, sem jamais dividir essa soberania. Há uma frase, por exemplo, da correspondência com Perrier, no momento em que este, Piera Aulagnier, Valabrega e outros deixam a Escola Freudiana por causa do passe. Lacan escreve: "Vocês me deixaram sozinhos quando da fundação da escola" , o que é discutível, já que eles foram seus co-fundadores. M esmo na adversidade não se funda uma associação sozinho, funda-se com outras pessoas.

Compreendo essa declaração de outra forma: "Fundo sozinho como sempre estive na minha relação com a psicanálise e como cada um é sempre sozinho na sua relação com a psicanálise", daí essa declaração de Lacan de que "o analista na 
prática só recebe autoridade dele mesmo e não da instituição". Nisso, claro, estou inteiramente de acordo. Mas no momento dessa cisão ele escreve: "Ou vocês estão todos comigo ou todos sem mim". Por que ele adota tal posi ção? Por que não diz: "Todos comigo e todos sem mim", o que seria no fundo um reconhecimento do que pode haver de partilhado numa instituição e ao mesmo tempo de respeito pela singularidade de cada um. Ora, ele adota uma posição de "todos comigo ou todos sem mim". Então, é preciso fazer vassalagem e é essa posição de soberania que, penso, se transmitiu na herança lacaniana e continua a causar problema hoje.

LDP - 0 berço da psicanálise poderia ter sido outro senãoViena?

RM - A priori, penso que não, porque se tratava de uma conjuntura excepcional como acontece uma vez por século, quando todas as condições são reunidas para que algo aconteça. Schorske descreveu com perfeição o que era aViena do fim do século XIX e início do século XX, onde não havia uma tradição filosófica, mas haviaW Wttgenstein; em Viena, a irmã deWittgenstein faz análise com Freud. Há um ambiente cultural favorável ao nascimento da psicanálise.

Não é suficiente, foi preciso que houvesse o gênio pessoal de Freud e foi um caminho muito complicado e sinuoso o que o conduziu à invenção da psicanálise depois de passar pela hipnose, pela catarse etc. Mas o que considero muito importante do ponto de visto político - e penso que em Freud isso está presente do início ao fim - é o que ele diz numa carta a Romain Rolland, de maneira exemplar: "Passei minha vida me desfazendo de minhas ilusões e das ilusões da humanidade". Isso é verdade tanto na prática analítica quanto no plano sociopolítico.

Penso que não há ruptura no que diz Freud entre a prática analítica e sua análise do coletivo, da guerra, do mal-estar na civilização ou na religião. É a partir do momento em que ele se liberta progressivamente de todos os condicionamentos, de tudo que limita - a hipnose limita, a catarse também - e, por fim, ele encontra o que limita menos, o que deve libertar o sujeito. Esse é 0 caminho excepcional de Freud. Então, é preciso analisar suas relações pessoais com sua família, sua cultura, esta facilidade de se desfazer muito rápido, mesmo com erros, de tudo o que o marcou no início.

LDP - 0 livro negro da psicanálise chocou os meios psicanalíticos franceses pela violência dos ataques contra Freud e Lacan. Qual sua opinião sobre ele?

RM - Na época do lançamento, o Libération me pediu uma crítica. Perguntei qual era a opinião deles. Disseram-me que achavam o livro medíocre, detestável. Eu Ihes disse que eles é que deveriam escrever isso. E tive prazer de ver duas críticas que não vinham de psicanalistas, principalmente a do editor do jornal Charlie 
Hebdo. Cabe à imprensa tomar posições, pois os psicanalistas podem parecer que defendem seus interesses, o que não impede que desenvolvam argumentos contra o que se passa com esse tipo de fenômeno.

0 que é interessante no editorial do Charlie Hebdo é que ele mostra que não é um fenômeno que diz respeito apenas à psicanálise, mas existe também em relação à literatura, à filosofia. No centenário do nascimento de Jean-Paul Sartre, o Le Nouve Observateur deu na capa: "É preciso queimar Sartre?". Ou, como mostrou Jean-Luc N ancy no LeM onde, há um grau profundo de ataque a Heidegger e Freud. Ora, o que os cognitivistas ressuscitam é o respeito ao código positivista com o menosprezo de tudo o que o pensamento freudiano desenvolveu e que não se reduz nem se resume na metafísica, nem na ciência, no sentido que se dá ao termo até Freud. Querem recuar um século!

LDP - No Livro negro da psicanálise faz- se, entre outras coisas, a crítica do caráter não científico da psicanálise. Freud pretendeu fundar uma ciência? 0 que é a psicanálise, afinal?

RM - Eu diria que Freud, de início, sob a aparência de querer inscrever a psicanálise no campo das ciências da natureza, retoma termos do vocabulário já existente. Ele não parece inventar nenhum vocabulário novo, o 'inconsciente' já existe; 0 'recalque', Schopenhauer já tinha usado; o 'sonho', claro, já era conhecido. Ele vai ao encontro de um certo pensamento antigo, mesmo o Eros platônico, mas subverte esses conceitos herdados.

Tomemos, por exemplo, o sonho. Ele mostra o que já tinha sido dito: que 0 sonho realiza ou antecipa a realização de um desejo; mas mostra quais são as leis desse funcionamento. $E$, mostrando essas leis, há qualquer coisa que dá um aspecto científico que ele descobre e estabelece, que tem ao mesmo tempo laços com uma tradição científica, mas que está em ruptura com esse conceito de ciência.

De maneira geral, Freud mostra bem, na sua auto-análise e na análise dos sonhos, que isso passa também pela literatura, por Sófocles, por Hamlet e por outros. É a partir da implicação subjetiva que se constrói a psicanálise, o que nenhuma ciência fez até então. É preciso observar que Freud e a psicanálise foram rotulados de ciência judaica, burguesa, atéia e, hoje, de não-ciência, o que significa que esta etiqueta encobre algo, sempre é a mesma coisa. 0 que é insuportável é a natureza sexual, desde a etiologia sexual da histeria até a natureza sexual da transferência na análise.

Por exemplo, quando queimam os livros de Freud num auto-de-fé em Berlim, não se diz que é porque ele é judeu. Diz-se: “Contra o exagero da vida instintiva que desagrega o espírito e pela nobreza da alma humana, eu jogo no fogo os textos de Sigmund Freud". Portanto, é porque Freud trata dos recônditos da alma humana, da vida pulsional, sexual. 
A propósito de ciência burguesa, deve-se observar que os russos foram os primeiros a traduzir Freud em uma língua estrangeira. Eles pensaram que a revolução psicanalítica poderia ser posta a serviço da revolução bolchevique, que as crianças poderiam, separando-se de suas famílias, tornar-se filhos da Nação. 0 Estado teria o controle das crianças. Mas logo que perceberam que as fantasias primordiais das crianças, fantasias de sedução, de cena primitiva, de castração eram necessariamente ligadas ao pai ou à mãe, eles perceberam que a natureza sexual das relações no seio da família não seria nunca dissolvida nem poderia ser desenvolvia pelo pai ou mãe da N ação. Deu-se então a caça aos psicanal istas e eles desapareceram.

Quando, em 1970, fomos ao Congresso deTbilissi, na era soviética, percebi uma coisa extraordinária: era possível para a universidade fazer uma tese sobre Lacan, porque Lacan entrava no domínio da lingüística, mas sobre Freud era totalmente impossível, porque em Freud chocava o que chamaram de pan- sexualismo.

LDP - Freud estava excluído desde quando?

RM - Desde a época de Stálin.

LDP - Como se pode definir a psicanálise, já que ela não é uma ciência?

RENÉ - Podemos recorrer ao que disse Freud a Romain Rolland: élibertar-se das ilusões pessoais, que vêm da família, da educação e que nos marcaram pessoalmente, e ao mesmo tempo das ilusões veiculadas pela sociedade, seja pela religião, pela política ou por seu modo de organização social. Mesmo nas instituições psicanalíticas o discurso psicanalítico em todo o seu rigor não foi ainda suficientemente levado em conta para que essas instituições mostrem o que seria na prática a revolução psicanalítica em toda a sua força. Lacan dizia que o discurso psicanalítico deveria produzir um laço social livre de toda a obscenidade imaginária. Ainda estamos longe, mas pode-se dizer que a psicanálise éjovem, se ela sobreviver.

LDP - Dizer "se ela sobreviver" implica o reconhecimento de um risco. Qual?

RM - $O$ risco vem, sobretudo, dos psicanalistas. Se eles não sabem manter suas posições, se se comprometem com o retorno de todas as formas de condicionamento do outro ou do exercício de poder sobre o outro e se aceitam compromissos com o Estado e com as "novas antigas" formas de terapia. Mas, por exemplo, Borch-Jakobsen, um dos responsáveis pelo Livro negro da psicanálise, eu conheço bem, ele é um incomparável leitor de arquivos. Mas tudo depende da utilização que ele faz destes arquivos, de sua leitura, de seus códigos de interpretação.

Os arquivos não falam por eles, tudo depende de como são lidos. Vê-se que também é sobre a natureza sexual da transferência que a coisa Ihe parece inacei- 
tável. E nisso, ele toma tudo o que o biógrafo de Freud, Ernest Jones, diz sobre o assunto para tirar argumentos contra Freud quando, na realidade, se trata de Jones. Então, volta-se à questão da recusa da natureza sexual da transferência ou da neurose em geral que se manifesta na transferência, e da libertação que a transferência supõe, a libertação possível.

0 que é de difícil aceitação é não apenas a natureza sexual da neurose e da transferência, mas a libertação que ela é suscetível de produzir, eé por isso que é preciso voltar a formas de exercício de poder sobre o outro ou de condicionamento do outro, como na educação. 0 risco é que os psicanalistas tentem eles próprios instaurar formas de exercício de poder no interior da própria psicanálise.

LDP - A escuta psicanalítica tem um papel na psiquiatria, no tratamento do sofrimento psíquico dos doentes mentais, ou deve ser encarada como uma via privilegiada para as neuroses?

RM - Eis uma pergunta complicada. É certo que para Freud a psicanálise não se aplicava senão à neurose. Ele diz explicitamente que ela não se aplica à psicose, ressalvando que isso poderia vir de uma idiossincrasia pessoal, que talvez fosse porque ele não suportava a grande loucura.

É bem verdade que Lacan, suportando melhor a loucura - sua própria loucura, aliás, já que ele dizia "eu não sou ainda suficientemente louco". Ou, ainda, podia ficar fascinado pela escritura de Joyce e querer escrever um pouco como 0 irlandês, com uma profusão de neologismos que o tornam um pouco hermético, 0 que 0 confina à loucura. Mas é certo que Lacan abriu o caminho aos tratamentos das psicoses. Houve Melanie Klein na Inglaterra, com a psicanálise de crianças, e chamo a atenção para o fato de que ela sempre falou de psicanálise de crianças e não de psicoterapia de crianças.

Penso que a mistura da psicanálise com a psiquiatria ou mesmo o lugar da psicanálise na universidade é muito problemático porque, como Freud, aliás, tinha alertado, a psicanálise corre o risco de se tornar a factotum da psiquiatria, a factotum da universidade. E vê-se que é o que se passa agora: introduz-se a psicanál ise em todos os lugares e ela não será senão uma coisa entre outras, mesmo na universidade. U ma pitada de psicanálise, uma pitada de comportamentalismo, de cognitivismo etc. E assim, creio, ela perde sua alma.

Recebida em 6/ 3/ 2006. 